\title{
Comprehensive Role of Otorhinolaryngologists in the Management of Headache: A Prospective Tertiary Care Centre Based Study
}

\author{
Rajwant Kaur Kamal* \\ Department of Otorhinolaryngology, Government Medical College and Hospital, Patiala, Punjab, India.
}

*Corresponding author: Rajwant Kaur Kamal, Department of Otorhinolaryngology,

Government Medical College and Hospital, Patiala, Punjab, India.

\begin{abstract}
Background: Headache is most common complaint of human being. Classified into primary (migraine, tension headache and trigeminal neuralgia) and secondary (infectious, vascular and drug induced). Sinugenic headache is deep seated, dull aching with fullness and heaviness in sinus area. The purpose of study to assess the comprehensive role of otorhinolaryngologists in the diagnosis of headache and to evaluate the efficacy of medical and surgical management of patients presented with headache. 200 patients reported to rhinology clinic with headache. Detailed history, head and neck examination routine blood investigation, fundus examination \& anterior rhinoscopy, radiological investigations X-ray paranasal sinuses, skull \& cervical spine and direct nasal endoscopy was and CT paranasal sinus preoperatively done.

Results: 200 patients assessed using VAS analog scale before and after treatment dividing into four groups: resolved, improved, no change, and worsened' group; p value was statistically significant in resolved and improved group whereas non-significant in no change and worsened group. 129 patients had non-sinugenic headache; $29(22.48 \%)$ with cervical cause, Migraine 24 (18.60\%) and ophthalmic $23(17.48 \%)$ respectively; dental and vascular 19 (14.72\%) each, and psychogenic headache in $13(10.07 \%)$ and trigeminal neuralgia in 2 patients $(1.55 \%)$. 96.12\% were relieved by medical treatment whereas 71 patients of sinugenic headache $21.12 \%$ were treated successfully with medical treatment. One refused surgery, 50/55 (90.90\%). Improvement assessed by SNOTT-22 pre- and post-surgery that was statistically significant p value-0.002.
\end{abstract}

Conclusion: Headache need comprehensive management. Sinugenic headache managed successfully initially with medical treatment and refractory cases by surgical intervention with equal efficacy.

Key words: Sinugenic headache; Otorhinolaryngologists; SNOTT-22; Contact point headache

Abbreviations: VAS score: Visual Analogue; SNOTT-22: Sino Nasal Outcome Test; BT: Bleeding time; CT: Clotting Time; CTPNS: Computed Tomography Scan Of Para Nasal Sinuses; HIS: International Headache Society; DNS: Deviated Nasal Septum

\section{Background}

Headache is very annoying, distressing, and common condition both for patient as well as physician. It is the second most common complaint with which patient present to general physician, otorhinolaryngologists, neurologist, othropaedician, ophthalmologist and psychiatrist [1]. Headache can be primary (migraine, tension or cluster headache and trigeminal neuralgia) or secondary (infectious, vascular and drug induced). Primary headache is often associated with gastrointestinal or sensory symptoms and effected by various environmental factor [2]. Another classification of headache is superficial and deep which is often helpful in locating the source of headache. Superficial pain is felt exactly at the site of insult and is of burning quality often associated with increase in blood pressure and movement, on the other hand deep pain also known to be referred pain is often dull aching in nature due to involvement of the muscle and blood vessel and often associated with hypotension or nausea and vomiting [3]. 
International Headache Society (IHS) and the American Academy of Otolaryngology- Head and Neck Surgery (AAO-HNS) described various conditions of sinugenic headache. Sinusitis pain comes from inflamed and engorged nasal structures like turbinate, nasofrontal ducts, Ostia and superior nasal spaces. Sinugenic headache is usually deep, dull aching with complaints of fullness and heaviness, and more during awakening, and seldom associated with nausea and vomiting. IHS classification place paranasal sinus disease in the etiology of headaches and facial pain in section
$11.5[4,5]$. The mechanism of type of headache effects the role of otorhinolaryngologist in identification, diagnosis, and treatment of the underlying causes. As the symptoms are overlapping for both sinugenic and non sinugenic headache or even exist simultaneously in the same patient more liberal diagnostic approach needed [6]. So, the present study done to assess the comprehensive role of otorhinolaryngologist in the management of headache (sinugenic and non sinugenic) and to evaluate the efficacy of medical and surgical treatment for sinugenic headache (Figure 1).

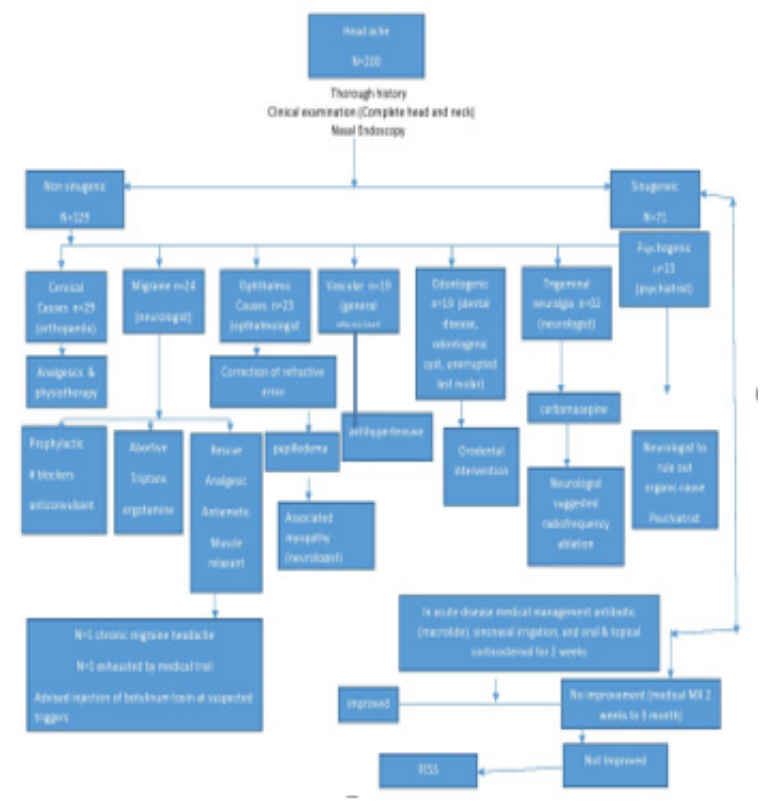

Figure 1: Algorithm for the management of Headache.

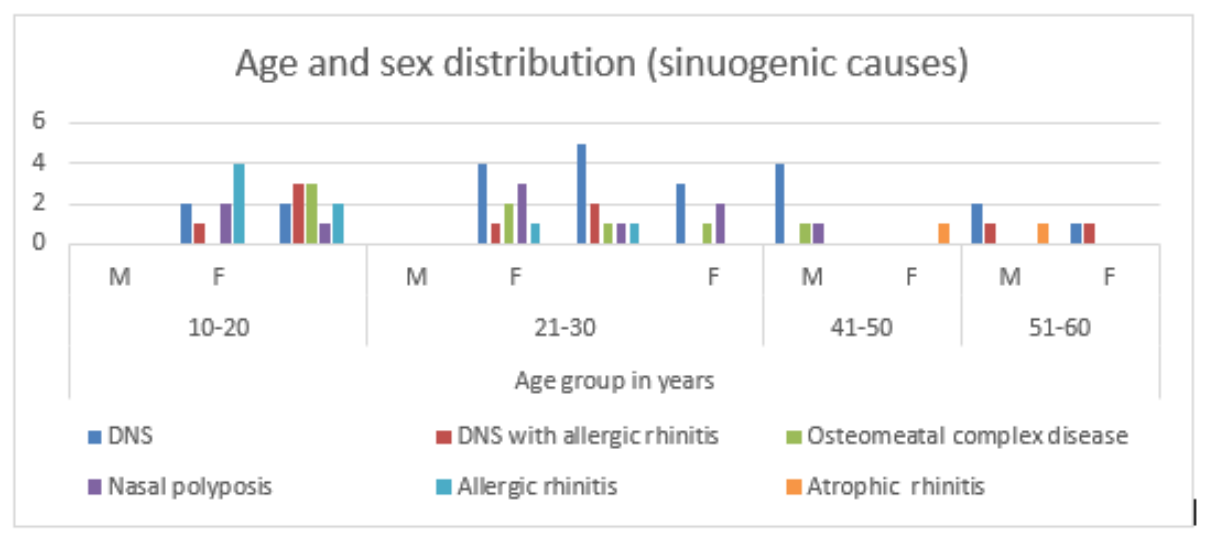

Figure 2: Age and sex distribution (sinugenic causes).

\section{Methods}

The present study is a tertiary centre based prospective study on 200 patients reported to rhinology clinic during the time of June 2017-July 2018 with the complaints of headache along with other overlapping symptoms. Institutional ethical committee clearance has been obtained as it contain human participants.
These patients came directly or were referred from other departments like ophthalmology, general medicine, neurology, orthopedic and psychiatry. Inclusion criteria are headache localized to the periorbital, frontal or zygomotemporal regions of more than 2 weeks duration with clinical feature suggestive of sinusitis (based on detailed history, systemic examination, ENT 
examination and investigations). Headache that improves with use of topical anesthesia mainly $4 \%$ lignocaine was used plus local nasal decongestant. Worsens with change in pressure like diving, flight or with climatic changes. So, following diagnostic criteria are included:

a) Headache usually recurrent, non-seasonal, and not associated with fever or localized tenderness in the region of sinuses and erythema.

b) Headache or facial pressure that developed simultaneously after acute onset or acute-on-chronic rhino sinusitis.

Exclusion criteria are patient having severe headache suggestive of intracranial disease or clinically other than sinugenic headache; not consenting to participate. Patients of age group above 10 years and less than 60 years of either sex were included in the study. All the patients suffering from headache for more than 2 weeks duration, mainly located in the frontal, malar, vertex, temporal and neck region. A thorough detailed history was taken with clinical and systemic examination done to rule out all possible causes such as hypertension, cluster and tension headache, migraine, neurological, ophthalmological, and various other causes. Detailed history of headache regarding its localization, mode of onset, duration, periodicity (continuous or intermittent), progressive or non-progressive, intensity of pain and its radiation, type of pain, any aggravating or relieving factors, duration of each attack as well as frequency, time of attack any associated symptoms of nausea and vomiting, and sinugenic causes like nasal obstruction, discharge, anosmia, epistaxis, sneezing etc. was taken (Figure 2).

\section{VAS Score of Group I and II}

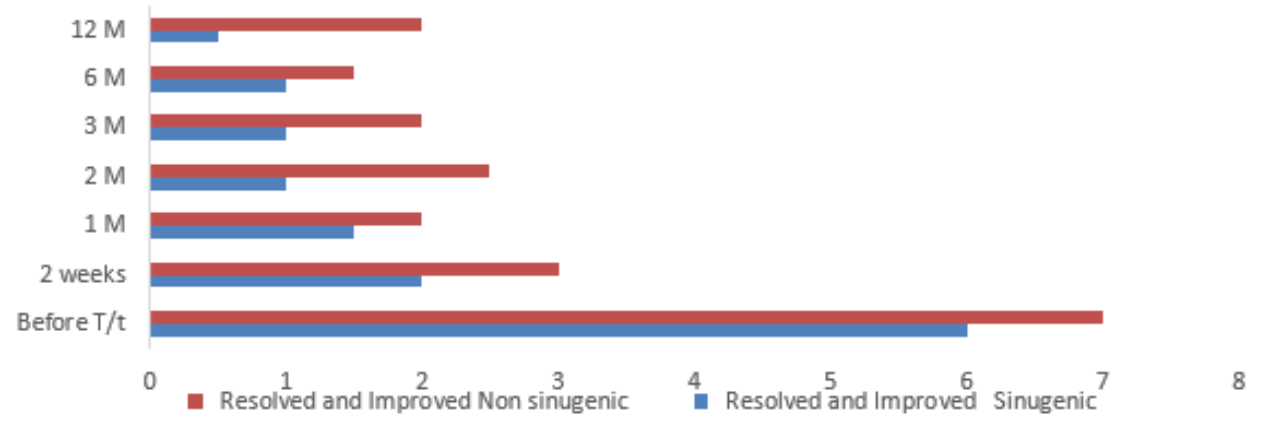

Figure 3: VAS score in sinugenic and non sinugenic patient before and after treatment at 2 weeks, 1, 2, 3, 6 and 12 month in group I \& II (3a) and III \& IV (Figure 3b).

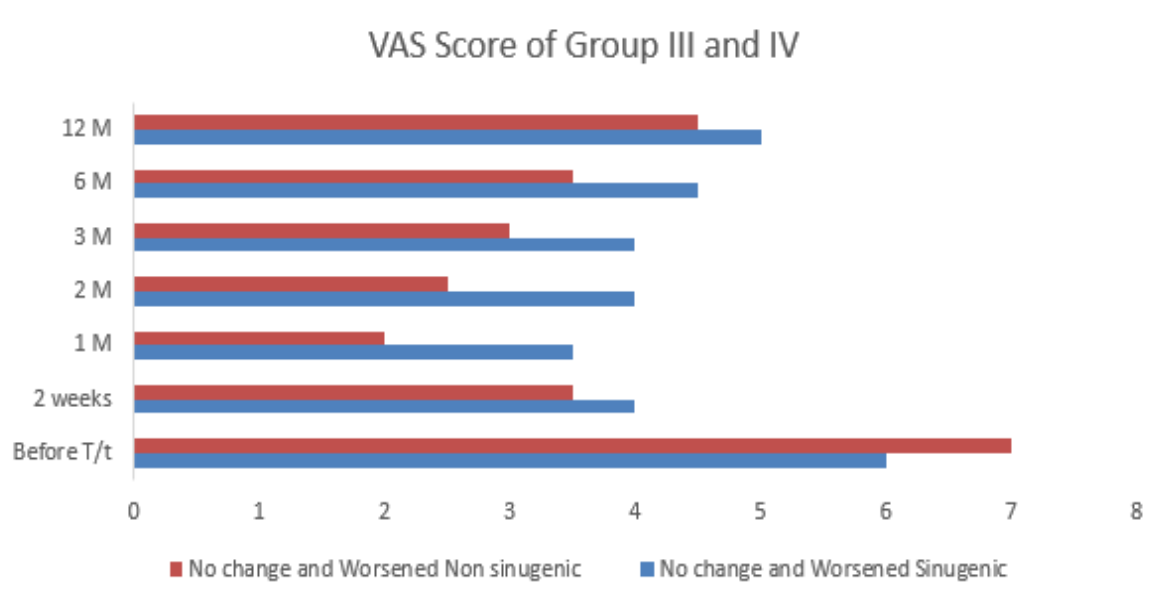

Figure 3b: VAS Score of Group III and IV.

All the 200 patients referred to rhinology clinic with presumptive diagnosis of rhino sinusitis, were subjected to routine complete blood examination with BT, CT, urine for albumin, sugar and microscopic examination, and X-ray cervical spine both (anterio-posterior and lateral view) selectively in patients complaining of neck pain. All patients underwent anterior and posterior rhinoscopy, rigid digital nasal endoscopy examination under local anesthesia (4\% lignocaine+nasal decongestant) with 0 - 
and 30-degree endoscope, to assess the condition of nasal mucosa, nasal septum and conchae, nasopharyngeal end of Eustachian tube or nasopharynx, also to see any sign of draining mucous from the sinuses. When sinugenic cause were highly suspected then patient was subjected to radiological investigations in the form of X-ray paranasal sinuses water's view but plain and contrast enhanced CT was only done, to evaluate for any anatomical variations other than normal. So once diagnosis was confirmed patients were advised surgery. MRI was done in selected cases having overlapping symptoms. Headache intensity was graded with 10-point visual analog scale (VAS) $0-10$, here 0 signified absence of pain and 10 most intense pain. For further analysis, after post treatment patients were divided into four categories; 'resolved' group consisted of patients who rated headache that was almost completely resolved, 'improved' group (group I\&II) was defined as patients who is after treatment VAS score was lower than they're before treatment score, 'no change' group comprised patients who showed no change in the VAS score, and the 'worsened' group (group III\&IV) included patients who's after treatment. After treatment VAS score in sinugenic and non sinugenic patient were assessed 2 weeks, 1, 2, 3 , 6 and 12 months in group I \& II and III \& IV.

Effectiveness was determined for management strategies. These were as follows:

1. Upfront medical therapy (when sinusitis was suspected). Those who were not responded and pinpointing the other aetiology were managed by combined effort of concerned specialties.

2. Upfront surgical management guided by CT scan of paranasal sinus.
Sinonasal-Nasal Outcome Test (SNOT-22) questionnaire was used to assess the improvement in patients who underwent surgery (pre and postoperatively after 6 months of surgery). Each item score was measured, and higher scores indicated worse symptom severity as follows: $0=$ "no problem"; 1 = "very mild problem"; 2 = "mild or slight problem"; 3 = "moderate problem"; 4 = "severe problem"; and $5=$ "problem as bad as it can be".

\section{Results}

A prospective study was conducted on 200 patients complaining of headache reported to rhinology clinic during time interval of June 2017-December 2018 with complaints of headache and other overlapping symptoms. These patients came directly or referred from other specialties like ophthalmology, general medicine, neurology, othropaedician, and psychiatry. Patients above 10 and less than 60 years included with mean age $36.58+12.28$. Majority of the non sinugenic patients fell in the 41-50 age group, followed by $31-40$. Whereas sinugenic patients were more in 21-30 age group followed by 10-20 age group (Figure 3).

So, the most common cause of non-sinugenic headache was cervical pain among 29 (22.48\%) patients including 13 male and 16 females mostly above 40 age group. Migraine and ophthalmic cause were other common cause of non sinugenic headache involving $24(18.60 \%)$ and $23(17.82 \%)$ patients, respectively. Migraine was more prevalent among female whereas ophthalmic cause was equally common in both sexes. Other causes were dental and vascular involving 19 (14.72\%) number of patients of each cause whereas vascular cause was found mostly above 40 years next cause was psychogenic headache in $13(10.07 \%)$ with slightly more predilection for female population. Other cause was trigeminal neuralgia involving $2(1.55 \%)$ patients (Table 1$)$.

Table 1: Age and sex wise distribution of patients with non sinugenic headache $(n=129)$.

\begin{tabular}{|c|c|c|c|c|c|c|c|c|c|c|}
\hline \multirow{2}{*}{ Cause of Pain } & \multicolumn{2}{|c|}{ Age group in years $10-20$} & \multicolumn{2}{|c|}{$21-30$} & \multicolumn{2}{|c|}{$31-40$} & \multicolumn{2}{|c|}{$41-50$} & \multicolumn{2}{|c|}{$51-60$} \\
\hline & M & $\mathbf{F}$ & $\mathbf{M}$ & $\mathbf{F}$ & M & $\mathbf{F}$ & $\mathbf{M}$ & $\mathbf{F}$ & M & F \\
\hline Cervical pain & 0 & 0 & 2 & 2 & 2 & 4 & 5 & 4 & 4 & 6 \\
\hline Ophthalmic disorder & 2 & 3 & 1 & 0 & 6 & 2 & 2 & 4 & 1 & 2 \\
\hline Migraine & 1 & 2 & 1 & 6 & 0 & 5 & 1 & 4 & 0 & 1 \\
\hline Dental causes & 1 & 1 & 2 & 3 & 2 & 4 & 4 & 1 & 0 & 1 \\
\hline Vascular causes & 0 & 0 & 1 & 0 & 3 & 1 & 4 & 2 & 5 & 3 \\
\hline Psychogenic causes & 0 & 1 & 2 & 1 & 0 & 3 & 2 & 1 & 1 & 2 \\
\hline Trigeminal neuralgia & 0 & 0 & 0 & 0 & 0 & 0 & 0 & 1 & 1 & 0 \\
\hline
\end{tabular}

Table 2: Age and sex wise distribution of patient with sinugenic headache according to mucosal contact point. ( $\mathrm{n}=71$ ).

\begin{tabular}{|c|c|c|c|c|c|c|c|c|c|c|}
\hline & \multicolumn{2}{|c|}{ Age group (in years) $10-20$} & \multicolumn{2}{|c|}{$21-30$} & \multicolumn{2}{|c|}{$31-40$} & \multicolumn{2}{|c|}{ 41-50 } & \multicolumn{2}{|c|}{$51-60$} \\
\hline & M & $\mathrm{F}$ & M & $\mathrm{F}$ & M & $\mathrm{F}$ & M & $\mathrm{F}$ & M & $\mathrm{F}$ \\
\hline DNS & 3 & 2 & 2 & 4 & 5 & 3 & 4 & 0 & 2 & 1 \\
\hline DNS With Allergic Rhinitis & 3 & 1 & 3 & 1 & 2 & 0 & 0 & 0 & 1 & 1 \\
\hline Osteomeatal complex Disease & 0 & 0 & 3 & 2 & 1 & 1 & 1 & 0 & 0 & 0 \\
\hline Nasal Polyposis & 0 & 2 & 1 & 3 & 1 & 2 & 1 & 0 & 0 & 0 \\
\hline Allergic Rhinitis & 5 & 4 & 2 & 1 & 1 & 0 & 0 & 0 & 0 & 0 \\
\hline Atrophic Rhinitis & 0 & 0 & 0 & 0 & 0 & 0 & 0 & 1 & 1 & 0 \\
\hline
\end{tabular}


Among 29 patients of cervical pain only $15 \%$ exhibited osteophytes and osteoarthritis on the cervical region radiology rest having almost normal finding, pain was significantly relieved by taking analgesic and physiotherapy as advised by othropaedician. 23 patients of the ophthalmic cause, 20 had refraction error and after correction they had significant improvement, 2 had papilledema (due to retinal hemorrhage) included in resolved and improved group, only one among them had no relief due to associated myopathy included in group III. Rest 13 patients referred to neurologist to rule out any organic cause and after all the necessary investigation and examination when no specific etiology was found referred to psychiatrist. After treatment only 7 patients were completely relieved of their headache 4 patients had partial relief whereas 1 patient with slight improvement in symptoms (12 patient in resolved and improved category of VAS) and 1 patient had no relief at all. Migraine disorder in 24 patients were found to be more common in the age group 21-30, followed by 31-40 with female preponderance and almost all the patients were benefited by ergot preparation except 1 patient who was having associated allergic rhinitis. Dental and vascular causes were treated according to their causes with significant relief of pain. One female patient of trigeminal neuralgia was relieved successfully with medical management whereas the male patient had worsening of symptom referred to neurologist.

All the 71 patients of sinugenic headache and its symptoms underwent nasal endoscopy and CT PNS. As in that pain was drastically improved using local anesthesia and nasal decongestant. Based on endoscopic examination and CT scan DNS (36.61\%), DNS with allergic rhinitis (16.90\%), osteomata complex disease (14.08\%), nasal polyp (11.26\%), allergic rhinitis (18.30\%), and atrophic rhinitis (2.81\%) were detected. (Table 2) The preoperative mean Lund Mackay score was 9.75 .

Septoplasty was done for DNS or DNS with spur. According to the presence of mucosal contact point on diagnosis, functional endoscopic sinus surgery including middle turbinectomy, ungiectomy, and ethmoidectomy like procedure were done with no adverse event during the procedure, so postoperative was 10.309 which was statistically significant ( 0.002 value) (Table 2).

Age and sex distribution(sinugenic causes) 13 patients of allergic rhinitis and 2 patients of atrophic rhinitis were treated medically, only 8 patients among allergic rhinitis had significant improvement but the rest 5 had partial relief. Medical treatment was given in form of topical nasal decongestant, topical and oral corticosteroid, in active cases antibiotics (macrolides) were added. Initially it was given for 2 weeks then for 1, 2, and 3 months depending upon the patient response. Other 56 patients one patient refused for surgery, rest 55 after medical fitness. An informed consent underwent surgery including septoplasty, middle turbinectomy, uncinectomy, and ethmoidectomy according to the anatomic variation. Overall success rate of the surgery in relieving headaches was measured by using SNOTT-22 score which represents the most validated and widely utilized measure for chronic rhinosinusitis [7]. Headache was completely relieved in 31 (56\%) patients, 19 (35\%) patients reported a decrease in the headache intensity whereas in 4 (7\%) patients it remained unchanged and 1 (2\%) patient had worsening of headache intensity. Pre- and post-operative (after 6 months) scores were analyzed and found to have significant correlation (preoperative SNOTT 22 was 17.145 and postoperative was 10.309 which was statistically significant, $\mathrm{p}<0.002$ value).

\section{Discussion}

Sinugenic headache is often associated with significant morbidity and remains a challenge for both clinician and patient and mostly diagnosed by exclusion. As sinugenic headache patient may have multifactorial etiology and comorbities, so these patients always challenging to manage, and mostly require the interdisciplinary care to achieve good result. 8 The present study evaluated the comprehensive role of otorhinolaryngologist along with other concerned specialties for the management of headache. And at same time the efficacy of medical and surgical treatment was assessed without much difference if sinugenic and non-sinugenic headache was rightly diagnosed. Currently 'contact point headache' is more highlighted than the classic entities of acute and chronic rhinitis as a primary cause of sinugenic headache. It is a syndrome secondary to mucosal contact points that can be deviated nasal septum (DNS), DNS with septal spurs, concha bullosa, hypertrophied inferior turbinate, uncinated bulla, medialized or paradoxical middle turbinate and large ethmoidal bulla in the Sino nasal cavities may be without any sign of inflammation, hyperplastic mucosa, purulent discharge, and sinonasal polyps or masses. Sinugenic entities like sinusitis sometimes mimics or precipitate neurogenic syndromes. As it is common in sphenoid sinusitis. It may cause visual disturbance, or cranial neuropathy [9]. Many studies suggest that surgical removal of such mucosal contact points is more effective than medical therapy to improve quality of life $[10,11]$. In present study 200 patients were enrolled with chief complaint of headache. Out of these 200, 129 (64.5\%) were categorized as non sinugenic cause and rest 71 (35.5\%) sinugenic cause of headache after thorough history taking and complete head and neck examination, and nasal endoscopy after local anesthesia. Among non sinugenic headache, major cause was cervical pain (29), followed by migraine (24), ophthalmic cause (23), vascular (19), and psychogenic headache (13). Similar study conducted by Foroughi pour et al., in 2011, studied 58 patients presented with sinugenic headache. All patients were assessed for 6 months by otorhinolaryngologist and neurologist, and finally diagnosed with migraine (68\%), tension-type headache $(27 \%)$, and chronic sinusitis with recurrent acute episodes in (5\%) of the patients [12].

Yet another study done by Eross et al in 2007 found that among 100 self-diagnosed headache patients in primary care and general population, migraine remain the most common diagnosis in $52 \%$, 
only 3\% had sinugenic headache and $9 \%$ had non classifiable headache. Most common reason for misdiagnosis may be headache location, associated and aggravating features [13]. Similar study conducted by Kumar KS et al in 2019 suggested prevalence of sinugenic headache in $13 \%$ whereas migraine in $53 \%$ and tension headache in $31 \%$ [14]. Yet another study conducted by Debdulal Chakraborty et al in 2018 had 98 patients of sinugenic headache out of 200. Among sinugenic patient's majority of them had DNS (40.81\%) or osteomeatal complex disease (34.69\%) followed by nasal polyps (12.25\%) and allergic rhinitis (8.17\%) [15]. In the present study, among 71 patients of sinugenic headache DNS (36.61\%), DNS with allergic rhinitis (16.90\%), osteomeatal complex disease (14.08\%), nasal polyp (11.26\%), allergic rhinitis (18.30\%), and atrophic rhinitis (2.81\%) were detected, with highest incidence among 21-30 years followed by 11-20 years. Similarly, in the study conducted by Pramod Kumar et al. majority of the headache cases were seen in the 10-30 years [16]. In most of the patients had headache localized to forehead, periorbital area followed by glabella, malar area, and with more than one site. The mean headache frequency was 4 episodes per month and mean headache severity was 1.5 hours. The average initial onset of headaches was 18 months, ranging from 2 weeks to 8 years. Post treatment patients were assessed using VAS analogue scale and divided into four groups; resolved group, improved, no change group, and worsened group. Present study suggested that VAS score was statistically significant in group I\& II in both non sinugenic and sinugenic patients whereas it was not significant in group III \& IV. That result was very much like the study done by Wee et al, in 2015 on characteristic of rhinogenic headache which noted statistically significant VAS score in group I \&II and non-significant in group III\& IV in pre- and post-operative patients with sinugenic headache [17].

Our study suggested that 129 patients of non sinugenic headache $96.12 \%$ were relieved of their headache successfully by otorhinolaryngologist in collaboration with other specialties. These patients initially had sign and symptoms of sinusitis, which was managed with topical decongestant, topical or oral steroids, but due to others overlapping symptoms concerned with relative specialty. So, with proper diagnosis most of the non-sinugenic headache patients were managed successfully. Among 71 patients of sinugenic headache $21.12 \%$ were treated successfully with medical regime for minimum of 3 months in form of local corticosteroid, whereas in acute and active stage macrolides antibiotics along with oral corticosteroid (only when indicated), whereas rest 56 patients who were refractory to medical treatment were advised surgery. Among them one patient refused to give consent for surgery. $50 / 55(90.90 \%)$ patients had significant improvement assessed using SNOTT-22 score 6 months after surgery. Whereas overall surgical success rate was only $80 \%$ in Wee et al study. Similar study conducted by Willatt and Low suggested 63\% relieved in intensity of chronic headache [18]. But Parsons and Batra studied that
91\% had relief in intensity of sinugenic headache after FESS [19]. Similarly, Clerico et al. noted $79 \%$ of improvement in sinugenic headache not only in severity but also in intensity [20]. On the other hand, Ragbad et al found significant objective and subjective improvement in management of headache without any difference between the line of treatment either medical or surgical. That was in accordance with present study as patients with sinugenic headache were first treated on medical line and only refractory cases and patient with contact point headache were taken up for the surgery with significant improvement in intensity and frequency of headache [21]. Currently no data is available that suggest which line of treatment is superior to the other for the management of sinugenic origin of headache.

\section{Conclusion}

Headache is a symptom which is universally experienced by human being. Usually, these patients have multifactorial etiology. So, the present study suggested that initial medical regime followed by surgery in refractory cases were equally effective with little difference. Moreover, the present study management protocol was very fruitful and encouraging to reduce the cost of treatment and decreasing the psychological burden of surgery and its potential risk of its complication. Such patients require interdisciplinary care to overcome the challenges to manage them. A detailed history and thorough evaluation are required to rule out whether it is of sinugenic or non sinugenic origin. Sinugenic headache patients need radio logical assessment and nasal endoscopy to find the status of the paranasal sinuses and mucosal contact points. Non sinugenic patients can be managed with $96.12 \%$ success rate in collaboration with other specialties and all sinugenic patients firstly should be treated on medical line then only refractory cases should be considered for surgery with $90.90 \%$ success rate. A thorough diagnostic workup is required to find out the etiologies of headache and this is the main key in management of patients with sinugenic and non sinugenic headache. There are few limitations of present study firstly a small sample size and secondly short duration of follow up for assessment of management in VAS score especially in no change and worsened group. Despite these short comings present study management protocol will provide interest for the future aspirants to reinvestigate it, specially validating the less common causes of sinugenic headaches such as mucosal contact point.

\section{Acknowledgement}

None.

\section{Conflict of Interest}

Author has no conflict of Interest.

\section{References}

1. Belamkar SK, Tugave J (2017) The usefulness of nasal endoscopy in diagnosing and managing sinugenic headache. Medpulse Int J ENT 4: 45-48. 
2. Martin V, Elkind A (2004) Diagnosis and classification of Primary Headache disorders. In Standards of care for headache diagnosis and treatment Chicogo (II) National Headache Foundation. PP. 4-18.

3. Ahmad Z, Himani, Srivastava VK (2018) Headache \& Sinus Disease. A Clinical Study, Int J R \& R, 5(6).

4. Cady RK, Dodick DW, Levine HL, Schreiber CP, Eross EJ, et al. (2005) Sinus headache: A neurology, otolaryngology, allergy, and primary consensus on diagnosis and treatment. Mayo Clin Proc 80(7): 908-916.

5. (2004) Headache Classification Committee of the International Headache Society. International Classification of Headache Disorders $\left(2^{\text {nd }}\right.$ Edn.) Cephalgia. 24: 1-151.

6. Grylas A (2016) Allergic rhinitis and chronic daily headache: is there a link? Curr Neurol Neurosci Resp 16(4): 33.

7. Hopkins C, Gillett S, Slack R, Lund V, Browne J (2009) Psychometric validity of the 22-item Sinonasal Outcome Test. Clin Otolaryngol 34(5): 447-454.

8. West B, Jones NS (2001) Endoscopy-negative, computed tomography negative facial pain in a nasal clinic. Laryngoscope 111(4pt 1): 581-586.

9. Hirose Y, Hirota Y, Yokokawa D, Ohira Y, Ikusaka M (2016) Acute sphenoiditis involving the second branch of trigeminal nerve. QJM 109(11): 745-746.

10. Cantone E, Castagna G, Ferranti I, Cimmino M, Sicignano S, et al. (2015) Concha bullosa related headache disability. Eur Rev Med Pharmacol Sci 19(13): 2327-2330.

11. La Mantia I, Grillo C, Andaloro C (2017) Rhinogenic contact point headache: surgical treatment versus medical treatment. J Craniofac Surg 29(3): 228-230.
12. Foroughipour M, Sharifian SMR, Shoeibi A, Nazanin Ebdali Barabad, Mehdi Bakhshaee (2011) Causes of sinus headache in patients with a primary diagnosis of sinus headache. Eur Arch Otorhinolaryngol 268(11): 1593-1596.

13. Eross E, Dodick D, Eross M. (2007) The sinus, Allergy and Migraine Study (SMAS). Headache 47(2): 213-224.

14. Kumar KS, Devan PP (2019) Do you really have sinus headache? Int J Otorhinolaryngol H\&N Surg 5: 554-559.

15. Chakraborty D, Guha R, Dev AX, Kesarwaani S. (2018) A clinical study of headache in relation to chronic rhinosinusitis. Sch J App Med Sci 6: 3718-3721.

16. Kumar P, Chawla P.(2000) A correlative study of sinusitis versus headache. Indian J Otolaryngol Head Neck Surg 52(2): 125-127.

17. Jee HW, Ji-Eun L, Sung-Lyong H, Jin MS, Dong-Young K (2015) Prospective Study on the Characteristics and Postoperative Improvement of Rhinogenic Headache. J Rhinol 22: 6-10.

18. Low WK, Willatt DJ (1995) Headache associated with nasal obstruction due to deviated nasal septum. Headache 35: 404-406.

19. Parsons DS, Batra PS. (1998) Functional endoscopic sinus surgical outcomes for contact point headaches. Laryngoscope 108(5): 696-702.

20. Cleric DM, Evan K, Montogomery L, Lanza DC, Grabo D (1997) Endoscopic sinonasal surgery in the management of primary headaches. Rhinol 35(3): 98-102.

21. Ragab SM, Lund VJ, Scadding G. (2004) Evaluation of the medical and surgical treatment of chronic rhinosinusitis: a prospective, randomized, controlled trial. Laryngoscope 114(5): 923-930. 